Jurnal Indonesia Sosial Teknologi: p-ISSN: 2723 - 6609

e-ISSN : 2745-5254

Vol. 2, No. 10 Oktober 2021

\title{
PENGARUH HARGA, PROMOSI DAN KUALITAS PELAYANAN TERHADAP LOYALITAS PELANGGAN MELALUI KEPUASAN PELANGGAN SEBAGAI VARIABEL INTERVENING
}

\author{
Dadi Kuswandi ${ }^{1}$, Guyub Nuryanto ${ }^{2}$ \\ Fakultas Ekonomi, Universitas Gunadarma ${ }^{1,2}$ \\ Email: kuswandi@staff.gunadarma.ac.id ${ }^{1}$,guyub@staff.gunadarma.ac.id ${ }^{2}$
}

\begin{abstract}
Abstrak
Saat ini teknologi yang semakin berkembang di seluruh dunia yang tidak bisa di pungkiri lagi. Dengan adanya teknologi yang semakin berkembang pesat akan dapat membantu mempermudah masyarakat dalam melakukan aktivitas sehari-hari karena kemudahan dalam mengakses teknologi. Tujuan dari penelitian ini adalah untuk mengetahui dan menganalisis apakah variabel Harga, Promosi dan Kualitas Pelayanan berpengaruh signifikan terhadap Loyalitas Pelanggan melalui Kepuasan Pelanggan sebagai variabel interveningnya. Studi kasus pada pengguna Traveloka di Kelapa Dua, Tangerang. Metodologi yang dipergunakan dalam penelitian ini adalah pengumpulan data melalui penyebaran kuesioner secara online dan menggunakan teknik purposive sampling pada 135 responden yang telah menggunakan aplikasi Traveloka di Kelapa Dua, Tangerang. Pengujian ini dilakukan dengan program SPSS versi 20 dan AMOS versi 23. Pada tahap analisis dilakukan uji validitas, uji reliabilitas, dan Structural Equation Model (SEM). Hasil penelitian menunjukkan variabel harga, promosi dan kualitas pelayanan memiliki pengaruh yang positif terhadap kepuasan pengguna Traveloka di Kelapa Dua, Tangerang, variabel promosi memiliki pengaruh yang positif terhadap loyalitas pelanggan dan kepuasan pelanggan berpengaruh positif terhadap loyalitas pelanggan, sedangkan harga dan kualitas pelayanan tidak berpengaruh positif terhadap Loyalitas Pengguna Traveloka di Kelapa Dua, Tangerang.
\end{abstract}

Kata kunci: Harga; Promosi; Kualitas Pelayanan; Kepuasan Pelanggan; Loyalitas Pelanggan

\section{Abstract}

Nowadays technology is growing all over the world that can't be denied anymore. With technology that is growing rapidly, it will be able to help make it easier for people to carry out daily activities because of the ease of accessing technology. The purpose of this study is to determine and analyze whether the variables Price, Promotion and Service Quality have a significant effect on Customer Loyalty through Customer Satisfaction as the intervening variable. Case study of Traveloka users in Kelapa Dua, Tangerang. The methodology used in this research is data collection throughquestionnaire distribution online and using purposive sampling technique on 135 respondents who have used the Traveloka application in Kelapa Dua, Tangerang. This test was carried out using SPSS version 20 and AMOS version 23. In the analysis phase, validity, reliability, andtests were carried out 
Structural Equation Model (SEM). The results showed that the variables of price, promotion and service quality had a positive influence on the satisfaction of Traveloka users in Kelapa Dua, Tangerang, the promotion variable had a positive effect on customer loyalty and customer satisfaction had a positive effect on customer loyalty, while price and service quality had no positive effect. on Loyalty of Traveloka Users in Kelapa Dua, Tangerang.

Keywords: Price; Promotion; Service quality; Customer satisfaction; Customer loyalty

\section{Pendahuluan}

Saat ini teknologi yang semakin berkembang di seluruh dunia yang tidak bisa di pungkiri lagi. Dengan adanya teknologi yang semakin berkembang pesat akan dapat membantu mempermudah masyarakat dalam melakukan aktivitas sehari-hari karena kemudahan dalam mengakses teknologi.

Berdasarkan survei yang telah dilakukan oleh Asosiasi Jasa Internet Indonesia pada tahun 2016, data statistik yang diperoleh dalam penggunaan internet terus mengalami peningkatan yang cukup signifikan dalam jumlah penggunaan internet telah mencapai 132,7 juta pengguna atau dapat dikatakan sudah melampaui setengah dari total penduduk di Indonesia yaitu sebesar 51, 8\%.

Seiring dengan meningkatnya jumlah internet, hal tersebut juga memberikan dampak positif bagi sektor perusahaan atau bisnis yang menggunakan fasilitas internet.

Dengan meningkatnya pengguna internet, akan mendorong perusahaan untuk terus tumbuh, berkontribusi, serta melakukan inovasi dengan perkembangan ekonomi di Indonesia.

Tabel 1.1

Komposisi Pengguna Internet Indonesia

\begin{tabular}{cccc}
\hline No & Usia & Jumlah Pengguna & $\begin{array}{c}\text { Jumlah Pengguna } \\
\text { (Presentase) }\end{array}$ \\
\hline 1 & $10-24$ Tahun & 24,4 Juta & $18,4 \%$ \\
\hline 2 & $25-34$ Tahun & 32,3 Juta & $24,4 \%$ \\
\hline 3 & $35-44$ Tahun & 29,2 Juta & $29,2 \%$ \\
\hline 4 & $45-54$ Tahun & 23,8 Juta & $18 \%$ \\
& 55 Tahun & 13,2 Juta & $10 \%$ \\
\hline
\end{tabular}

Bahwa masyarakat jaman sekarang dengan melakukan pembelian kebutuhan sehari-hari secara online, di era digital seperti saat ini banyak masyarakat yang melakukan pembelian tiket pesawat, tiket kereta api, dan melakukan reservasi hotel secara online melalui situs-situs penjualan tiket pesawat dan hotel karena dinilai sangat mempermudah, cepat, dan praktis dalam pembelian. 
Sehingga perusahaan jasa seperti $e$-Commerce lebih banyak menekankan kepada kualitas pelayanan. Seperti halnya perusahaan Traveloka merupakan perusahaan yang bergerak dalam bidang pelayanan pemesanan tiket pesawat dan reservasi hotel secara online (Setyaningsih, 2014).

Salah satu perusahaan yang melaksanakan e-commerce adalah Traveloka. Traveloka merupakan salah satu perusahaan travel penyedia kebutuhan perjalanan. Traveloka sendiri merupakan perusahaan yang berasal dari Indonesia dan memiliki basis operasional di Jakarta.

Konsep awal berdirinya, Traveloka berfungsi sebagai mesin pencari untuk membandingkan harga tiket pesawat dari berbagai situs lainnya, dan pada pertengahan tahun 2013 Traveloka kemudian berubah menjadi situs reservasi tiket pesawat dimana pengguna dapat menggunakan pemesanan situs resminya.

Traveloka merupakan perusahaan yang menyediakan layanan tiket pesawat online dengan focus perjalanan di Indonesia dan luar negeri. Namun seiring dengan berjalannya waktu Traveloka menyediakan pembelian pelayanan booking hotel, pemesanan tiket kereta api, pulsa, internet, aktivitas dan rekreasi, tiket bus, dan travel.

Tabel 1.2

Lima Situs Penjualan Tiket Pesawat Secara Online Dengan Pengunjung Terbanyak Periode 2018

\begin{tabular}{ccccc}
\hline No & Nama Situs & $\begin{array}{c}\text { Peringkat di } \\
\text { Indonesia }\end{array}$ & $\begin{array}{c}\text { Jumlah } \\
\text { Pengunjung } \\
\text { (Juta Visitor) }\end{array}$ & $\begin{array}{c}\text { Jumlah } \\
\text { Pengunjung } \\
\text { (Presentase) }\end{array}$ \\
\hline 1 & Traveloka & 1 & 39,18 & $68,23 \%$ \\
\hline 2 & Tiket.com & 2 & 8,90 & $15,29 \%$ \\
\hline 3 & Booking.com & 3 & 3,97 & $6,91 \%$ \\
\hline 4 & Pegipegi.com & 4 & 2,97 & $5,17 \%$ \\
\hline 5 & Agoda.com & 5 & 2,40 & $4,17 \%$ \\
\hline
\end{tabular}

Sumber : www.similiarweb.com

Berdasarkan tabel 1.2 menunjukan bahwa Traveloka memimpin Online Travel Agent (OTA) penjualan tiket pesawat di Indonesia berdasarkan hasil survei dengan pengunjung terbanyak dengan total visitor yang tercatat di similiarweb untuk Traveloka mencapai 39,18 juta dengan presentase berjumlah $68,23 \%$.

Walaupun Traveloka memiliki basis operasional di Jakarta. Traveloka juga melayani tiket pesawat dan hotel secara online di beberapa Negara Asia Tenggara seperti Malaysia, Thailand, Vietnam, dan Filipina. Prsentase pengunjung Traveloka berdasarkan Negara dapat dilihat pada table 1.3.

Tabel 1.3

Presentase Pengunjung Situs Traveloka Berdasarkan Negara Periode 2019 


\begin{tabular}{ccc}
\hline No & Negara & Pengunjung (\%) \\
\hline 1 & Indonesia & $57,15 \%$ \\
\hline 2 & Vietnam & $17,36 \%$ \\
\hline 3 & Thailand & $12,96 \%$ \\
\hline 4 & Malaysia & $5,51 \%$ \\
\hline 5 & Filipina & $2,55 \%$ \\
\hline
\end{tabular}

Sumber : www.similiarweb.com

Tabel 1.3 menunjukkan bahwa para pengunjung Traveloka tidak hanya berasal dari Negara Indonesia tetapi juga berasal dari beberapa Negara Asia Tenggara lainnya. Pengunjung terbanyak situs Traveloka adalah Negara Indonesia dengan pengunjung sebesar $57,15 \%$.

Menurut (Alma, 2007), mengungkapkan bahwa kualitas pelayanan adalah suatu cara kerja perusahaan yang berusaha mengadakan perbaikan mutu secara terus-menerus terhadap proses, produk, dan service yang dihasilkan perusahaan.

Loyalitas pelanggan adalah komitmen yang dipegang secara mendalam untuk membeli atau mendukung kembali produk atau jasa yang disukai di masa depan meski pengaruh situasi dan usaha pemasaran berpotensi menyebabkan pelanggan baralih (Sembiring, 2014).

Kepuasan pelanggan merupakan suatu perasaan atau penilaian emosional dari pelanggan atas penggunaan suatu produk barang atas jasa dimana harapan dan kebutuhan mereka terpenuhi (Hilaliyah, 2017).

Kegiatan promosi dalam suatu perusahaan jasa menjadi hal yang penting untuk dilakukan, menurut (Kotler, 2012) Promosi (Promotion), adalah aktivitas yang mengkomunikasikan dan menginformasikan tentang suatu produk yang ditujukan kepada konsumen agar melakukan tindakan pertukaran dalam pemasaran (pembelian) terhadap produk tersebut.

Menurut (Kotler, Pemasaran, Jilid, \& II, 2005), harga adalah sejumlah uang yang dibebankan atas suatu produk, atau jumlah dari nilai yang ditukar konsumen atas manfaat-manfaat karena memiliki atau menggunakan produk tersebut.

Tujuan penelitian ini yaitu 1. Untuk mengetahui pengaruh Harga, Promosi dan Kualitas Pelayanan terhadap Kepuasan Pelanggan pada pengguna Traveloka di Kelapa Dua, Tangerang. 2. Untuk mengetahui pengaruh Harga, Promosi dan Kualitas Pelayanan terhadap Loyalitas Pelanggan pada pengguna Traveloka di Kelapa Dua, Tangerang. 3. Untuk mengetahui pengaruh Kepuasan Pelanggan terhadap Loyalitas Pelanggan pada pengguna Traveloka di Kelapa Dua, Tangerang. 4. Untuk mengetahui Harga, Promosi dan Kualitas Pelayanan terhadap Loyalitas Pelanggan melalui Kepuasan Pelanggan.

\section{Metode Penelitian}

Menurut (Sugiyono, 2016) objek penelitian adalah suatu atribut atau sifat atau nilai dari orang, objek atau kegiatan yang mempunyai variasi tertentu yang ditetapkan 
oleh peneliti untuk dipelajari kemudian ditarik kesimpulannya. Dalam penelitian ini yang menjadi subjek adalah para pengguna Traveloka di Kelapa Dua, Tangerang. Sedangkan Objek yang digunakan dalam penelitian ini adalah aplikasi travel, yaitu Traveloka.

\section{Jenis dan Sumber Data}

Jenis data yang digunakan dalam penelitian ini adalah data kuantitatif, yaitu penelitian yang berupa angka-angka dari hasil survey konsumen. Menurut ( $\underline{\text { Sugiyono, }}$ 2012) metode penelitian kuantitatif adalah metode penelitian yang digunakan untuk meneliti pada populasi atau sampel tertentu, pengumpulan data menggunakan instrumen penelitian, analisis data bersifat statistik, dengan tujuan untuk menguji hipotesis yang telah ditetapkan.

Sumber data yang digunakan dalam penelitian ini adalah data primer. Data primer adalah sumber data yang langsung memberikan data kepada pengumpul data (Sugiyono, 2012). Data primer dalam penelitian ini bersumber dari penyebaran kuesioner kepada pengguna Traveloka di Kelapa Dua, Tangerang.

\section{Populasi}

Populasi adalah wilayah generalisasi yang terdiri dari objek atau subjek yang mempunyai kualitas dan karakteristik tertentu yang ditetapkan oleh peneliti untuk

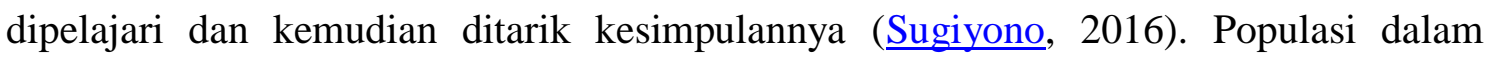
penelitian ini adalah pengguna Traveloka di Kelapa Dua, Tangerang.

\section{Sampel}

Sampel adalah sebagian dari jumlah dan karakteristik yang dimiliki oleh

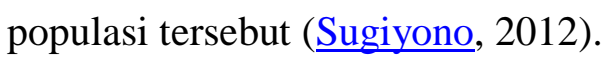

Teknik pengambilan sampel yang digunakan dalam populasi ini adalah teknik purposive sampling. Teknik purposive sampling merupakan teknik penentuan sampel dengan pertimbangan tertentu (Sugiyono, 2018). Jumlah sampel yang digunakan sangat mempengaruhi akurat atau tidaknya hasil yang didapatkan. Semakin banyak jumlah sampel yang digunakan maka akan semakin akurat data yang dapat dihasilkan. Jumlah yang sangat besar dibutuhkan ketika penelitian bersifat deskriptif, sebaliknya jumlah yang lebih sedikit akan dibutuhjan ketika penelitian hanya untuk menguji hipotesis.

Dalam penelitian ini menggunakan teknik penetuan sampel menurut (Hair, Black, Babin, Anderson, \& Tatham, 2006) menjelaskan ukuran sampel penelitian menggunakan rasio minimal 5 kali jumlah indikator. Jumlah indikator dalam penelitian ini adalah 22 dan dikalikan 5 sehingga minimal sampel dalam penelitian ini sebanyak 110 .

\section{Metode Pengumpulan Data}

Metode yang digunakan dalam penelitian ini untuk mengumpulkan data yaitu dengan menyebarkan kuesioner. Menurut ( 
pengumpulan data yang dilakukan dengan cara memberi seperangkat pertanyaan atau pernyataan tertulis kepada responden untuk dijawabnya. Kuesioner merupakan teknik pengumpulan data yang efisien bila peneliti tahu dengan pasti variabel yang akan diukur dan tahu apa yang bisa diharapkan dari responden.

Pengumpulan data dilakukan dengan memberikan atau menyebarkan daftar pertanyaan kepada responden. Teknik pengumpulan data yang digunakan dalam penelitian ini menggunakan kuesioner online melalui Google Form yang dilakukan dengan cara menyebarkan kuesioner untuk mendapatkan data-data yang berhubungan dengan masalah penelitian. Kuesioner dibagikan kepada para pengguna Traveloka di Kelapa Dua, Tangerang.

Pada penelitian ini pengukuran data menggunakan skala likert. Menurut (Sugiyono, 2018) Skala likert di gunakan untuk mengukur sikap, pendapat, dan persepsi seseorang atau sekelompok orang tentang fenomena sosial yang secara spesifik disebut variabel penelitian. Dengan skala likert, maka variabel yang diukur dijabarkan menjadi indikator variabel, kemudian indikator tersebut dijadikan sebagai tolak ukur menyusun item-item instrumen yang dapat berupa pernyataan dan pertanyaan.

\section{Uji Validitas}

Uji validitas digunakan untuk mengukur sah tidaknya suatu kuesioner. Suatu kuesioner dikatakan valid jika pertanyaan pada kuesioner mampu untuk mengungkapkan suatu yang akan diukur oleh kuesioner tersebut (In \& Asyik, 2019). Bukan hanya valid, tetapi harus mampu menjawab data apa yang dicari oleh peneliti. Adapun kriteria pengambilan keputusan untuk menentukan valid yaitu jika $r$ hitung lebih dari $r$ tabel pada taraf signifikan $5 \%$ atau 0,05 .

\section{Uji Reliabilitas}

Uji reliabilitas merupakan alat untuk mengukur suatu kuesioner yang merupakan indikator dari variabel atau konstruk. Suatu kuesioner dikatakan reliabel atau handal apabila jawaban seseorang pada pertanyaan konsisten atau stabil dari waktu ke waktu. Uji reliabilitas dalam penelitian ini menggunakan software SPSS dengan metode Cronbach Alpha (a). Menurut (Ghozali, 2005), suatu variabel dikatakan reliabel jika memberikan nilai a $>0,60$.

\section{Analisis Structural Model (SEM)}

Analisis structural equation model (SEM) bertujuan untuk menguji hubunganhubungan antara variabel yang ada pada sebuah model, baik itu antar-individu (Santoso, 2012).

Dalam analisis ini dimungkinkan memiliki beberapa variabel dependen dan variabel ini dimungkinkan akan menjadi variabel independen bagi variabel dependen yang lainnya.

Pada prinsipnya, model struktural untuk menguji hubungan sebab akibat antar variabel sehingga jika salah satu variabel diubah, maka terjadi perubahan pada variabel 
yang lain. Dalam penelitian ini, data diolah menggunakan Analysis of Moment Structure atau AMOS versi 23 (Primasanti \& Widodo, 2017).

Analisis SEM memungkinkan perhitungan estimasi seperangkat persamaan regresi yang simultan, berganda dan saling berhubungan. Karakteristik penggunaan model ini: (1) untuk mengestimasi hubungan dependen ganda yang saling berkaitan, (2) kemampuannya untuk memunculkan konsep yang tidak teramati dalam hubungan serta dalam menentukan kesalahan pengukuran dalam proses estimasi, dan (3) kemampuannya untuk mengakomodasi seperangkat hubungan antara variabel independen dengan variabel dependen serta mengungkap variabel laten.

\section{Hasil dan Pembahasan}

\section{Uji Validitas}

Tabel 4.5

Hasil Uji Validitas Harga (X1)

\begin{tabular}{cccc}
\hline Indikator & $\begin{array}{c}\text { Corrected } \\
\text { Item - } \\
\text { Total } \\
\text { Correlation } \\
\text { (R Hitung) }\end{array}$ & $\begin{array}{c}\mathrm{R} \\
\text { Tabel }\end{array}$ & Keterangan \\
\multicolumn{4}{c}{} \\
\hline Harga $\left(\mathrm{X}_{1}\right)$ \\
\hline $\mathrm{X}_{1 .} 1$ & 0,868 & 0,169 & VALID \\
\hline $\mathrm{X}_{1.2}$ & 0,871 & 0,169 & VALID \\
\hline $\mathrm{X}_{1.3}$ & 0,898 & 0,169 & VALID \\
\hline $\mathrm{X}_{1 .} 4$ & 0,863 & 0,169 & VALID \\
\hline
\end{tabular}

Sumber : Data Primer yang diolah, 2020

Tabel 4.6

Hasil Uji validitas Promosi $\left(\mathbf{X}_{2}\right)$

\begin{tabular}{cccc}
\hline Indikator & $\begin{array}{c}\text { Corrected } \\
\text { Item - } \\
\text { Total } \\
\text { Correlation } \\
\text { (R Hitung) }\end{array}$ & $\begin{array}{c}\mathrm{R} \\
\text { Tabel }\end{array}$ & Keterangan \\
\multicolumn{4}{c}{} \\
\hline Promosi $\left(\mathrm{X}_{2}\right)$ \\
\hline $\mathrm{X}_{2 .} 1$ & 0,862 & 0,169 & VALID \\
\hline $\mathrm{X}_{2 .} 2$ & 0,862 & 0,169 & VALID \\
\hline $\mathrm{X}_{2 .} 3$ & 0,894 & 0,169 & VALID \\
\hline $\mathrm{X}_{2 .} 4$ & 0,868 & 0,169 & VALID \\
\hline $\mathrm{X}_{2.5}$ & 0,862 & 0,169 & VALID \\
\hline
\end{tabular}

Sumber : Data Primer yang diolah, 2020

Tabel 4.7

Hasil Uji Validitas Kualitas Pelayanan ( $\left.\mathbf{X}_{3}\right)$ 
Dadi Kuswandi, Guyub Nuryanto

\begin{tabular}{cccc}
\hline Indikator & $\begin{array}{c}\text { Corrected } \\
\text { Item - } \\
\text { Total } \\
\text { Correlation } \\
\text { (R Hitung) }\end{array}$ & $\begin{array}{c}\mathrm{R} \\
\text { Tabel }\end{array}$ & Keterangan \\
\multicolumn{4}{c}{} \\
\hline Kualitas Pelayanan $\left(\mathrm{X}_{3}\right)$ \\
\hline $\mathrm{X}_{3.1}$ & 0,819 & 0,169 & VALID \\
\hline $\mathrm{X}_{3 .}$ & 0,863 & 0,169 & VALID \\
\hline $\mathrm{X}_{3.3}$ & 0,875 & 0,169 & VALID \\
\hline $\mathrm{X}_{3 .} 4$ & 0,850 & 0,169 & VALID \\
\hline $\mathrm{X}_{3.5}$ & 0,793 & 0,169 & VALID \\
\hline Sumber : Data Primer yang diolah, 2020
\end{tabular}

Tabel 4.8

Hasil Uji Validitas Kepuasan Pelanggan (Z)

\begin{tabular}{cccc}
\hline Indikator & $\begin{array}{c}\text { Corrected } \\
\text { Item - } \\
\text { Total } \\
\text { Correlation } \\
\text { (R Hitung) }\end{array}$ & $\begin{array}{c}\mathrm{R} \\
\text { Tabel }\end{array}$ & Keterangan \\
\multicolumn{4}{c}{} \\
\hline Kepuasan Pelanggan (Z) \\
\hline Z. 1 & 0,841 & 0,169 & VALID \\
\hline Z. 2 & 0,900 & 0,169 & VALID \\
\hline Z. 3 & 0,898 & 0,169 & VALID \\
\hline Z.4 & 0,773 & 0,169 & VALID \\
\hline
\end{tabular}

Sumber : Data Primer yang diolah, 2020

Tabel 4.9

Hasil Uji Validitas Loyalitas Pelanggan (Y)

\begin{tabular}{cccc}
\hline Indikator & $\begin{array}{c}\text { Corrected } \\
\text { Item - } \\
\text { Total } \\
\text { Correlation } \\
\text { (R Hitung) }\end{array}$ & $\begin{array}{c}\mathrm{R} \\
\text { Tabel }\end{array}$ & Keterangan \\
\multicolumn{4}{c}{} \\
\hline Loyalitas Pelanggan (Y) \\
\hline Y. 1 & 0,853 & 0,169 & VALID \\
\hline Y.2 & 0,838 & 0,169 & VALID \\
\hline Y.3 & 0,849 & 0,169 & VALID \\
\hline Y.4 & 0,849 & 0,169 & VALID \\
\hline Sub
\end{tabular}

Sumber : Data Primer yang diolah, 2020

Dari hasil perhitungan tabel diatas, diperoleh data yang menyatakan bahwa dari indikator yang diberikan kepada 135 responden ditemukan nilai Corrected Item-Total Correlation ( $\mathrm{R}$ hitung) lebih besar dari 0,169 ( $\mathrm{R}$ tabel) yang berarti bahwa seluruh pernyataan dalam penelitian ini hasilnya valid. 


\section{Uji Reliabilitas}

Tabel 4.10

Hasil Uji Reliabilitas

\begin{tabular}{cccc}
\hline Variabel & $\begin{array}{c}\text { Cronbach's } \\
\text { Alpha }\end{array}$ & $\begin{array}{c}\text { Nilai } \\
\text { Reliabel }\end{array}$ & Keterangan \\
\hline $\mathrm{X}_{1}$ & 0,897 & 0,60 & RELIABEL \\
\hline $\mathrm{X}_{2}$ & 0,919 & 0,60 & RELIABEL \\
\hline $\mathrm{X}_{3}$ & 0,895 & 0,60 & RELIABEL \\
\hline $\mathrm{Z}$ & 0,876 & 0,60 & RELIABEL \\
\hline $\mathrm{Y}$ & 0,868 & 0,60 & RELIABEL \\
\hline
\end{tabular}

Sumber : Data Primer yang diolah, 2020

Dari tabel diatas dapat diketahui bahwa nilai cronbach alpha dari masingmasing variabel yang diujikan nilainya diatas > 0.6. Suatu variabel dikatakan Reliabel jika nilai cronbach alpha $>0.6$. Maka dapat disimpulkan bahwa seluruh variabel dalam penelitian ini hasilnya reliabel.

\section{ANALISIS SEM}

Analisis data dalam penelitian ini dengan menggunakan AMOS versi 23.

\section{Membuat Path Diagram}

Path diagram atau diagram jalur digunakan untuk memberikan gambaran yang lebih jelas mengenai hubungan antar variable.

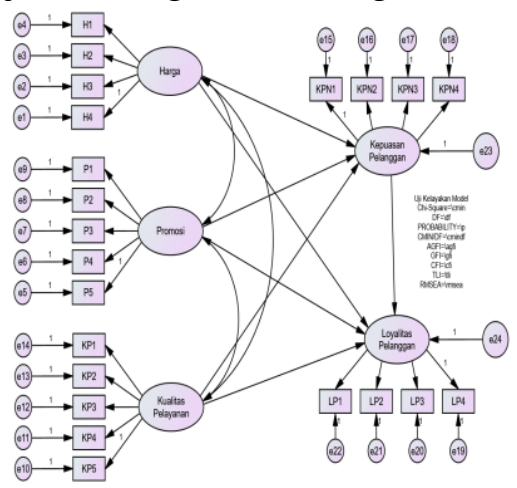

Sumber : Data primer diolah, 2020.

\section{Gambar 4.1 Path Diagram}

Diagram jalur di atas dapat diterangkan sebagai berikut :

1. Ada 5 variabel laten yaitu Harga, Promosi, Kualitas Pelayanan, Kepuasan Pelanggan dan Loyalitas Pelanggan.

2. Variabel laten Harga mempunyai 4 indikator pernyataan, Promosi 5 indikator pernyataan, Kualitas Pelayanan 5 indikator pernyataan, Kepuasan Pelanggan 4 indikator pernyataan dan Loyalitas Pelanggan 4 indikator pernyataan.

3. Ada 24 kesalahan pengukuran yaitu e1 sampai e24.

4. Ada 2 kesalahan residual yaitu e23 dan e24.

5. Diamsusikan variabel Harga, Promosi, Kualitas Pelayanan mempengaruhi variabel Kepuasan Pelanggan dan Loyalitas Pelanggan.

6. Model hubungan ini disebut recursive atau searah. 


\section{Uji Asumsi SEM}

Berikut adalah asumsi-asumsi dalam SEM sebelum menguji model :

\section{Ukuran Sampel}

Penelitian ini menggunakan 135 sampel, (Imam, 2014) menjelaskan bahwa ukuran sampel untuk teknik SEM antara 100 sampai 200, artinya ukuran sampel dalam penelitian ini sudah memenuhi jumlah sampel mínimum.

\section{Uji Normalitas}

Uji Normalitas digunakan untuk melihat apakah data dalam penelitian sudah terdistribusi normal atau tidak. Dalam output AMOS, uji normalitas dapat dilihat melalui assessment of normality dengan menggunakan kriteria critical ratio skewness value sebesar $<2,58$. Berikut adalah hasil output normalitas dalam penelitian ini :

Tabel 4.16

Hasil Uji Normalitas

\begin{tabular}{lrrrr}
\hline & skew & c.r. & Kurtosis & c.r. \\
\hline LP1 &, 667 & 3,165 &, 592 & 1,404 \\
\hline LP2 &, 741 & 3,515 &, 603 & 1,429 \\
\hline LP3 &, 362 & 1,718 & -193 &, 458 \\
\hline LP4 &, 394 & 1,869 &,- 022 &,- 053 \\
\hline KPN4 &, 628 & 2,977 &, 170 &, 403 \\
\hline KPN3 &, 408 & 1,936 &,- 143 &,- 339 \\
\hline KPN2 &, 553 & 2,625 & 0,99 &, 234 \\
\hline KPN1 &, 794 & 3,768 &, 353 &, 837 \\
\hline KP1 &, 765 & 3,267 &, 587 & 1,392 \\
\hline KP2 &, 593 & 2,812 &, 470 & 1,115 \\
\hline KP3 &, 605 & 2,871 &, 555 & 1316 \\
\hline KP4 &, 593 & 2,812 &, 470 & 1,115 \\
\hline KP5 &, 624 & 2,958 &, 538 & 1,276 \\
\hline P1 &, 512 & 2,426 &, 171 &, 407 \\
\hline P2 &, 669 & 3,173 &, 293 &, 695 \\
\hline P3 &, 657 & 3,114 &, 207 &, 491 \\
\hline P4 &, 519 & 2,464 &,- 022 &,- 052 \\
\hline P5 &, 641 & 3,041 &, 444 & 1,053 \\
\hline H1 &, 413 & 1,957 &, 075 &, 178 \\
\hline H2 &, 485 & 2,302 &,- 133 &,- 316 \\
\hline H3 &, 373 & 1,772 &,- 313 &,- 742 \\
\hline H4 &, 251 & 1,190 &,- 418 &,- 990 \\
\hline Multivariate & & & 13,450 & 2,404 \\
\hline
\end{tabular}

Sumber : Data primer yang diolah, 2020 
Berdasarkan Tabel 4.16 dapat diketahui uji normalitas secara multivariate berdistribusi normal karena nilai critical ratio (c.r) sebesar 2,404 $<2,58$ sehingga dapat dinyatakan bahwa data ini telah memenuhi asumsi normalitas.

\section{Uji Outlier}

Penentuan outlier data dilakukan dengan membandingkan data pada observations farthest from the centroid/mahalanobis distance dengan tabel critical values of chi square $\left(\mathrm{X}^{2}\right)$. Penentuan cut-off outlier ditentukan dengan memperhatikan jumlah indikator yang digunakan sebanyak 20 pada tingkat $\mathrm{p} \leq 0,001$ dengan menggunakan rumus $=\mathrm{CHIINV}(0,001 ; 20)$ sehingga cut -off dilakukan pada nilai 45,315 melalui program excel. Apabila nilai mahalanobis $d$-squared $>$ nilai cut off outlier maka terdapat outliers data

Tabel 4.14

Hasil Uji Outliers

\begin{tabular}{rrrr}
\hline $\begin{array}{r}\text { Observation } \\
\text { number }\end{array}$ & $\begin{array}{r}\text { Mahalanobis } \\
\text { d-squared }\end{array}$ & p1 & p2 \\
\hline 130 & 43,675 &, 004 &, 409 \\
\hline 33 & 39,350 &, 013 &, 520 \\
\hline 45 & 37,329 &, 022 &, 565 \\
\hline 109 & 36,968 &, 024 &, 402 \\
\hline 116 & 35,600 &, 034 &, 474 \\
\hline
\end{tabular}

Sumber : Data primer yang diolah, 2020.

Berdasarkan Tabel 4.17 dapat dilihat bahwa data tersebut merupakan 5 baris teratas dari tabel mahalanobis distance pada output AMOS yang memiliki nilai lebih kecil dari batas outlier yaitu sebesar 48,267. Sehingga tidak terdapat multivariate outlier pada penelitianini.

\section{Uji Kelayakan Model (Goodness of fit)}

Pengujian kelayakan model (Goodness of Fit) dilakukan untuk mengatahui seberapa fit model dengan data penelitian yang diperoleh. 


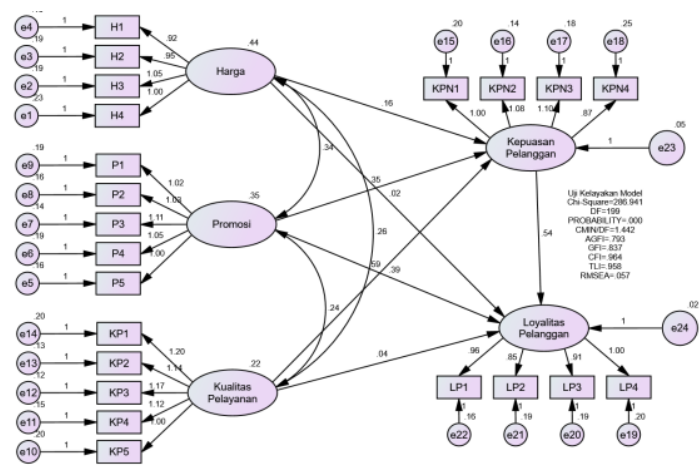

Sumber : Data primer yang diolah, 2020.

Gambar 4.2

\section{Structural Equation Model}

Berdasarkan output path diagram di atas, dibuat rangkuman hasil pengujian Goodness of fit yang dapat dilihat pada tabel berikut:

Tabel 4.18

\section{Hasil Pengujian Goodness of Fit}

\begin{tabular}{|c|c|c|c|}
\hline Kriteria & $\begin{array}{l}\text { Cut-off } \\
\text { Value }\end{array}$ & $\begin{array}{l}\text { Hasil } \\
\text { Model }\end{array}$ & Keterangan \\
\hline $\begin{array}{l}\text { Chi Square } \\
\left(\mathrm{X}^{2}\right) \\
(\mathrm{df}=199, \mathrm{p} \\
=0,050)\end{array}$ & $<232,911$ & 286,941 & Tidak Fit \\
\hline Probability & $\geq 0,05$ & 0,000 & Tidak Fit \\
\hline CMIN/DF & $\begin{array}{c}<2,00- \\
5,00\end{array}$ & 1,442 & Fit \\
\hline AGFI & $\geq 0,90$ & 0,793 & Tidak Fit \\
\hline GFI & $\geq 0,90$ & 0,837 & $\begin{array}{l}\text { Marginal } \\
\text { Fit }\end{array}$ \\
\hline CFI & $\geq 0,90$ & 0,964 & Fit \\
\hline TLI & $\geq 0,95$ & 0,958 & Fit \\
\hline RMSEA & $\leq 0,08$ & 0,057 & Fit \\
\hline
\end{tabular}

Sumber : Data primer yang diolah, 2020

Berdasarkan Tabel 4.18 dapat dilihat bahwa model secara keseluruhan memperlihatkan tingkat kesesuaian yang baik. Dari delapan kriteria yang digunakan untuk menilai layak atau tidaknya suatu model terdapat empat kriteria fit yaitu CMIN/DF, CFI, TLI, dan RMSEA. Terdapat tiga kriteria tidak fit yaitu Chi Square, Probability, dan AGFI dan terdapat satu kriteria marginal fit yaitu GFI. Dengan demikian model tidak dapat diterima yang berarti masih kurang sesuai antara model data.

\section{Modifikasi Model}

Apabila model tidak fit dengan data, langkah-langkah yang dapat dilakukan diantaranya: 
a. Memodifikasi model dengan menambahkan atau menghilangkan garis koneksi/garis hubung.

b. Menambah variabel jika tersedia.

c. Mengurangi variabel.

Modifikasi model yang dilakukan dalam penelitian ini didasari oleh teori yang dijelaskan (Imam, 2014) bahwa modifikasi model dapat dilakukan dengan melihat tabel modification indices. Pada tahap ini dilakukannya modifikasi model dengan tujuan mendapatkan model yang sesuai. Modifikasi ini dilakukan dengan menambahkan garis hubung. Dari hasil modifikasi tersebut, maka dihasilkan nilai goodness of fit yang baru pada gambar 4.3 sebagai berikut :

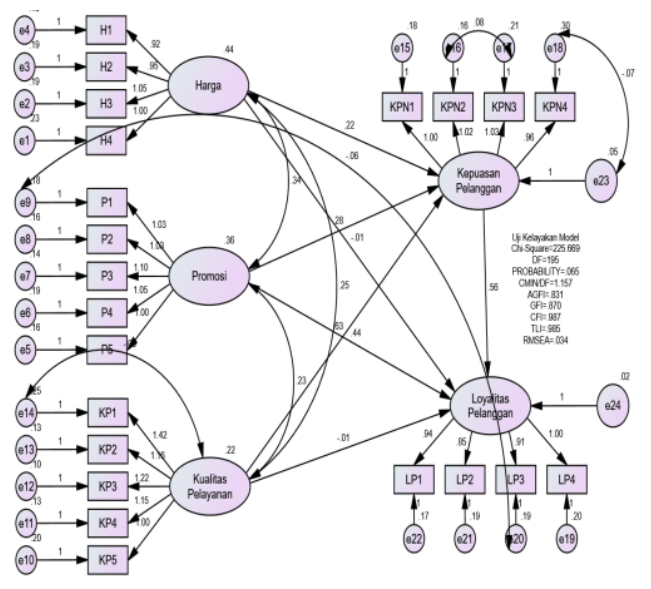

Sumber : Data primer yang diolah, 2020.

Berdasarkan hasil output diagram di atas, dibuat rangkuman hasil pengujian Goodness of Fit setelah dimodifikasi yang dapat dilihat pada tabel 4.19 sebagai berikut :

Tabel 4.19

Hasil Pengujian Goodness of Fit Modifikasi

\begin{tabular}{|c|c|c|c|}
\hline Kriteria & $\begin{array}{l}\text { Cut-off } \\
\text { Value }\end{array}$ & $\begin{array}{l}\text { Hasil } \\
\text { Model }\end{array}$ & Keterangan \\
\hline $\begin{array}{l}\text { Chi Square } \\
\left(\mathrm{X}^{2}\right) \\
(\mathrm{df}=195, \mathrm{p} \\
=0,050)\end{array}$ & $<228,579$ & 225,669 & Fit \\
\hline Probability & $\geq 0,05$ & 0,065 & Fit \\
\hline CMIN/DF & $\begin{array}{c}<2,00- \\
5,00\end{array}$ & 1,157 & Fit \\
\hline AGFI & $\geq 0,90$ & 0,831 & $\begin{array}{l}\text { Marginal } \\
\text { Fit }\end{array}$ \\
\hline GFI & $\geq 0,90$ & 0,870 & $\begin{array}{c}\text { Marginal } \\
\text { Fit }\end{array}$ \\
\hline CFI & $\geq 0,90$ & 0,987 & Fit \\
\hline TLI & $\geq 0,95$ & 0,985 & Fit \\
\hline
\end{tabular}




\begin{tabular}{llll} 
RMSEA & $\leq 0,08 \quad 0,034 \quad$ Fit \\
\hline
\end{tabular}

bahwa model secara keseluruhan memperlihatkan tingkat kesesuaian yang baik. Dari delapan kriteria yang digunakan untuk menilai layak atau tidaknya suatu model terdapat enam kriteria fit yaitu Chi Square, Probability, CMIN/DF, CFI, TLI, RMSEA dan dua kriteria marginal fit yaitu AGFI dan GFI, dengan demikian model dapat diterima yang berarti ada kesesuaian antara model dengan data.

\section{Pengujian Hipotesis}

Uji Hipotesis dilakukan dengan melihat nilai C.R dan nilai $\mathrm{P}$ pada regression weight apabila nilai critical ratio $(\mathrm{C} . \mathrm{R}) \geq 1,967$ atau nilai $\mathrm{P} \leq 0,05$ maka hipotesis diterima, hasil mengenai regression weight dapat ditunjukan pada tabel di bawah ini :

Tabel 4.20

\section{Regression Weight}

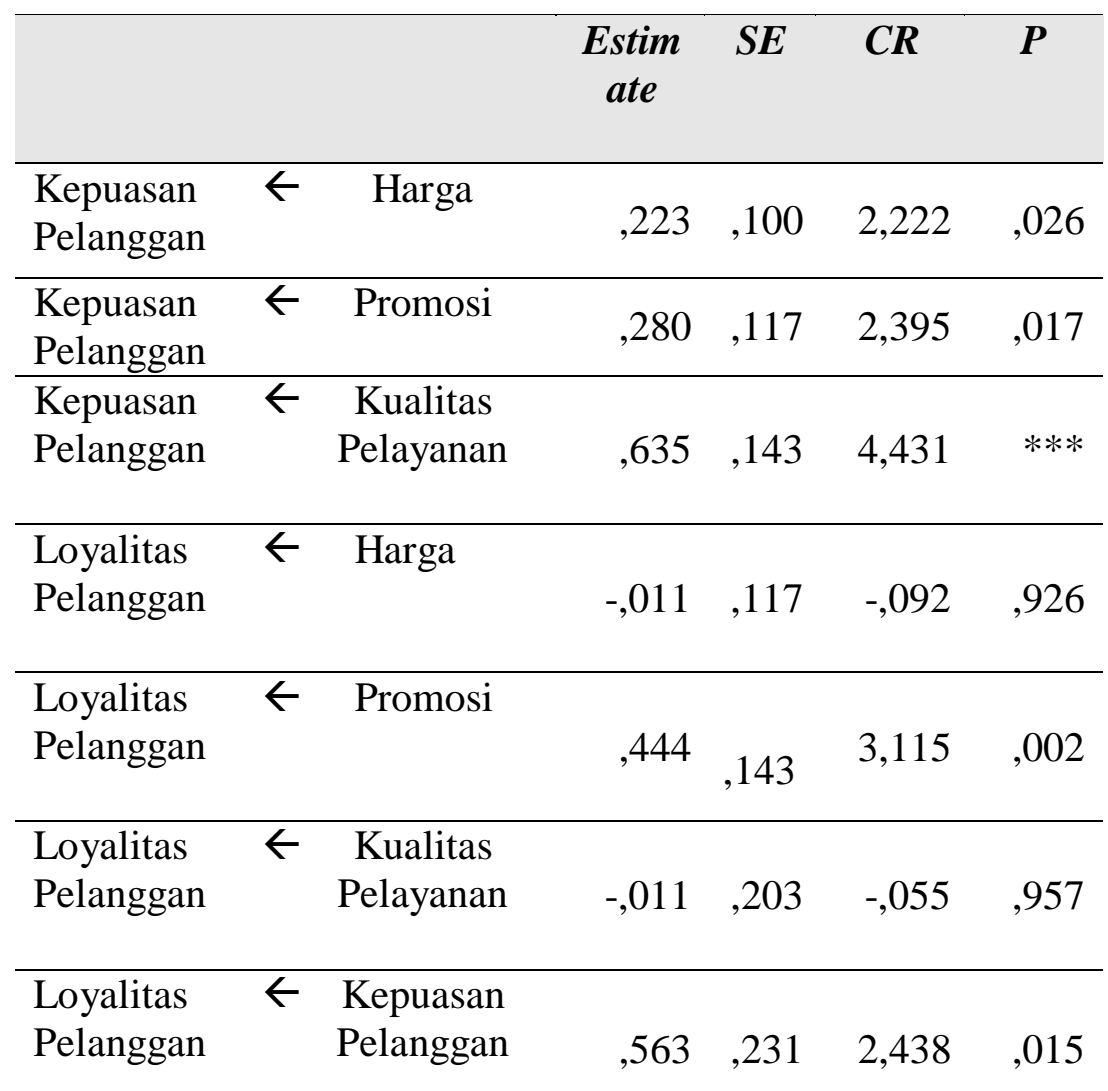

Sumber : Data primer yang diolah, 2020.

Tabel 4.20 dijadikan sebagai acuan utama untuk melakukan uji hipotesis dalam penelitian ini. Adapun hasil pengujian terhadap seluruh hipotesis yang diajukan dalam penelitian ini adalah sebagai berikut: 


\section{H1: Harga berpengaruh positif dan signifikan terhadap Kepuasan Pelanggan}

Berdasarkan data dari hasil penelitian diketahui bahwa nilai P-value sebesar $0,026 \leq 0,05$ dengan C.R sebesar $2,222 \geq 1,967$. Nilai ini menunjukan hasil yang memenuhi syarat sehingga dapat disimpulkan bahwa $\mathrm{H}_{1}$ dapat diterima. Berdasarkan hasil tersebut dapat disimpulkan bahwa harga yang dirasakan dapat menjadi penyebab terjadinya kepuasan. Sehingga semakin harga yang di tawarkan oleh Traveloka itu rendah maka semakin tinggi tingkat kepuasan pelanggan Traveloka. Harga disini diartikan bahwa dengan menggunakan Traveloka pengguna dapat memperoleh beberapa varian harga yang sesuai dengan kantong pengguna namun tidak menghilangi kualitas yang ditawarkan oleh Traveloka.

\section{H2: Promosi berpengaruh positif dan signifikan terhadap Kepuasan Pelanggan}

Berdasarkan data dari hasil penelitian diketahui bahwa nilai P-value sebesar $0,017 \leq 0,05$ dengan C.R sebesar $2,395 \geq 1,967$. Nilai ini menunjukan hasil yang memenuhi syarat sehingga dapat disimpulkan bahwa $\mathrm{H}_{2}$ dapat diterima. Berdasarkan hasil tersebut dapat disimpulkan bahwa promosi yang dirasakan dapat menjadi penyebab terciptanya kepuasan pelanggan Traveloka. Sehingga semakin gencar promosi yang diberikan oleh Traveloka, maka semakin tinggi tingkat kepuasan pelanggan Traveloka.

\section{H3: Kualitas Pelayanan berpengaruh positif dan signifikan terhadap Kepuasan Pelanggan}

Berdasarkan data dari hasil penelitian diketahui bahwa nilai P-value sebesar $0,000 \leq 0,05$ dengan C.R sebesar $4,431 \geq 1,967$. Nilai ini menunjukkan hasil yang memenuhi syarat sehingga dapat disimpulkan bahwa $\mathrm{H}_{3}$ dapat diterima. Berdasarkan hasil tersebut dapat disimpulkan bahwa kualitas pelayanan yang dirasakan dapat menjadi penyebab terciptanya kepuasan pelanggan Traveloka. Sehingga semakin aman dan nyaman pelayanan yang diberikan oleh Traveloka.

\section{H4: Harga tidak berpengaruh siginifikan terhadap Loyalitas pelanggan}

Berdasarkan data dari hasil penelitian diketahui bahwa nilai P-value sebesar $0,926 \leq 0,05$ dengan C.R sebesar $-0,092 \geq 1,967$. Nilai ini menunjukkan hasil yang tidak memenuhi syarat sehingga dapat disimpulkan bahwa $\mathrm{H}_{4}$ tidak dapat diterima. Berdasarkan hasil tersebut dapat disimpulkan bahwa meningkat atau menurunnya harga tidak akan diikuti dengan peningkatan maupun penurunan loyalitas pelanggan. Hal ini dikarenakan ketidakstabilan harga yang diketahui dalam menggunakan Traveloka tidak dapat diterima oleh responden dan menjadi pertimbangan untuk menggunakan traveloka.

\section{H5: Promosi berpengaruh positif dan siginifikan terhadap loyalitas pelanggan}

Berdasarkan data dari hasil penelitian diketahui bahwa nilai P-value sebesar $0,002 \leq 0,05$ dengan C.R sebesar $3,115 \geq 1,967$. Nilai ini menunjukkan hasil yang 
memenuhi syarat sehingga dapat disimpulkan bahwa $\mathrm{H}_{5}$ dapat diterima. Berdasarkan hasil tersebut dapat disimpulkan bahwa promosi dapat menjadi penyebab meningkatnya loyalitas pelanggan. Sehingga semakin gencar promosi yang dilakukan oleh Traveloka, maka semakin tinggi tingkat loyalitas pelanggan Traveloka.

\section{H6: Kualitas Pelayanan tidak berpengaruh signifikan terhadap Loyalitas Pelanggan.}

Berdasarkan data dari hasil penelitian diketahui bahwa nilai $\mathrm{P}$-value sebesar $0,957 \leq 0,05$ dengan C.R sebesar $-0,055 \geq 1,967$. Nilai ini menunjukkan hasil yang tidak memenuhi syarat sehingga dapat disimpulkan bahwa $\mathrm{H}_{6}$ tidak dapat diterima. Berdasarkan hasil tersebut dapat disimpulkan bahwa meningkatnya atau menurunnya kualitas pelayanan tidak akan diikuti dengan peningkatan maupun penurunan loyalitas pelanggan. Hal ini dikarenakan kualitas pelayanan yang diketahui dalam menggunakan Traveloka tidak dapat diterima oleh responden dan menjadi pertimbangan untuk loyalitas pelanggan Traveloka.

\section{H7: Kepuasan Pelanggan berpengaruh positif dan signifikan terhadap Loyalitas Pelanggan}

Berdasarkan data dari hasil penelitian diketahui bahwa nilai P-value sebesar $0,015 \leq 0,05$ dengan C.R sebesar $2,438 \geq 1,967$. Nilai ini menunjukkan hasil yang memenuhi syarat sehingga dapat disimpulkan bahwa $\mathrm{H}_{7}$ dapat diterima. Berdasarkan hasil tersebut dapat disimpulkan bahwa kualitas pelanggan dapat menjadi penyebab meningkatnya loyalitas pelanggan. Sehingga semakin tinggi tingkat kepuasan pelanggan Traveloka, maka semakin tinggi pula loyalitas pelanggan Traveloka.

\section{Kesimpulan}

Berdasarkan hasil penelitian ini adalah 1. Variabel harga, promosi dan kualitas pelayanan berpengaruh positif dan signifikan terhadap kepuasan pelanggan pengguna Traveloka di Kelapa Dua, Tangerang. 2. Variabel promosi berpengaruh positif dan signifikan terhadap loyalitas pelanggan pengguna Traveloka di Kelapa Dua, Tangerang. Sedangkan variabel harga dan kualitas pelayanan tidak berpengaruh siginifikan terhadap loyalitas pelanggan pengguna Traveloka di Kelapa Dua, Tangerang. 3. Variabel kepuasan pelanggan berpengaruh positif dan signifikan terhadap loyalitas pelanggan pengguna Traveloka di Kelapa Dua, Tangerang. 4. Variabel harga dan kualitas pelayanan berpengaruh positif dan signifikan terhadap loyalitas pelanggan pengguna Traveloka melalui kepuasan pelanggan. Sedangkan variabel promosi tidak berpengaruh siginifikan terhadap loyalitas pelanggan pengguna Traveloka melalui kepuasan pelanggan. 
Pengaruh Harga, Promosi dan Kualitas Pelayanan Terhadap Loyalitas Pelanggan

Melalui Kepuasan Pelanggan Sebagai Variabel Intervening

\section{Bibliografi}

Alma, Buchari. (2007). Manajemen Pemasaran dan Pemasaran Jasa, Bandung: Alfabeta.

Ghozali, Imam. (2005). Aplikasi Analisis Multivariate dengan program SPSS edisi 3. Semarang: Badan Penerbit Universitas Diponegoro.

Hair, Joseph F., Black, William C., Babin, Barry J., Anderson, Rolp E., \& Tatham, Ronald L. (2006). Multivariate data analysis 6th Edition. New Jersey: Prentice Hall.

Hilaliyah, Sari Atul. (2017). Pengaruh kualitas layanan dan kualitas produk yang di moderasi oleh suasana terhadap kepuasan pelanggan. Jurnal Bisnis Dan Manajemen, 4(2). https://doi.org/10.26905/jbm.v4i2.1699

Imam, Ghozali. (2014). Structural Equation Modeling Metode Alternatif dengan Partial Least Squares (PLS). Universitas Diponogoro: Semarang.

In, Agytri Wardhatul Khurun, \& Asyik, Nur Fadjrih. (2019). Pengaruh kompetensi dan independensi terhadap kualitas audit dengan etika auditor sebagai variabel pemoderasi. Jurnal Ilmu Dan Riset Akuntansi (JIRA), 8(8).

Kotler, Philip. (2012). Marketing management/Philip Kotler, Kevin Lane Keller. Pearson Education International.

Kotler, Philip, Pemasaran, Manajemen, Jilid, I., \& II, P. T. (2005). Indeks. Jakarta.

Primasanti, Yunita, \& Widodo, Imam Djati. (2017). Pengaruh Kemampuan Manajemen, Motivasi Franchise, Brand Image dan Promotion Strategy terhadap Keberhasilan USAha Franchise (Studi Kasus: Primagama Indonesia Timur). Teknoin, 23(2). https://doi.org/10.20885/teknoin.vol23.iss2.art9

Santoso, Singgih. (2012). Aplikasi SPSS pada statistik parametrik. Jakarta: PT Elex Media Komputindo.

Sembiring, Inka Janita. (2014). Pengaruh kualitas produk dan kualitas pelayanan terhadap kepuasan pelanggan dalam membentuk loyalitas pelanggan (Studi pada pelanggan McDonald's MT. Haryono Malang). Jurnal Administrasi Bisnis, 15(1).

Setyaningsih, Oktania. (2014). Pengaruh persepsi kualitas pelayanan e-commerce terhadap kepuasan pelanggan, kepercayaan dan loyalitas pada produk fashion. Jurnal Bisnis Dan Manajemen (Journal of Business and Management), 14(2), 6780 .

Sugiyono. (2012a). Metode Penelitian Kuantitatif, Kualitatif dan $\mathrm{R}$ \& D.Bandung:Alfabeta. Metode Penelitian Kuantitatif, Kualitatif Dan $R \quad \&$ D.Bandung:Alfabeta. https://doi.org/10.1017/CBO9781107415324.004 
Dadi Kuswandi, Guyub Nuryanto

Sugiyono. (2012b). Metode Penelitian Kuantitatif. 46-57.

Sugiyono. (2016). Metode Penelitian Kuantitatif, Kualitatif dan $R \& D$ (PT Alfabet). Bandung.

Sugiyono. (2018). Metode Penelitian Kuantitatif, Kualitatif, dan R\&D. Bandung: Alfabeta. 